\title{
127 MARIKINA CITY'S RESILIENCY AFTER TYPHOON RAMMASUN: PROPOSITION FOR LOCAL GOVERNMENT UNIT CLIMATE CHANGE ADAPTATION FRAMEWORK
}

Anthony B Abustan, ${ }^{1}$ Gilbert Delos Santos Bernardino $\mathrm{Jr}^{2}$. ${ }^{1}$ UERMMMCI, Quezon City, Philippines; ${ }^{2}$ Faculty of Management; Development Studies, University of the Philippines - Open University, Los Banos, Philippines

10.1136/bmjopen-2015-forum2015abstracts. 127

Background Marikina City was pummeled by Typhoon Rammasun last July 16, 2014. The calamity was caused by natural means, with addition of climate change as its catalyzing agent. This category 4 storm caused catastrophic damages to people and structures, leaving the city with millions of Philippine Pesos in loss.

Objectives Given these facts, the researchers aimed to assess their insights towards resilience after Typhoon Rammasun's wrath in the city. The assessment will be used by thelocal government in crafting the Local Government Unit (LGU) Climate Change Adaptation Framework.

Methods Using qualitative data inquiry, the study provided valuable perceptions in a multifaceted paradigm involving resiliency of the Marikina City community during Typhoon Rammasun. These perceptions were based from their in depth interviews, selected from 16 barangays of the local government unit using purposive sampling.

Result The result of the study showed synergism of different barangays and local government agencies in Marikina City in uplifting the resiliency as the focaltheme. The focal theme was reinforced by subthemes specifically: organized protocol of communications during disasters, cascading risk assessment information to the barangays, in depth discussion with the community's grassroots regarding the impacts of climate change drivers (rainy season, increase in average temperatures, etc.), and empowerment of local officials towards climate change adaptation policies \& programs.

Conclusion The study contributed a judicious depiction on the resilience of Marikina City in times of disaster. Moreover, it is recommended to have a proposition in the creation of a Climate Change Adaptation Framework that makes disaster risk reduction a local priority with a persuasive basis for policy and implementation. Furthermore, imbibing a philosophy of safety and resilience using awareness and education to all sectors of Marikina City will be of great help. Finally, reinforcing disaster preparedness with effective response will boost resiliency among Marikina City's constituents. 